\title{
EXPERIMENTAL STUDY ON TRANSPORT CHARACTERISTICS OF COASTAL BOULDERS BY TSUNAMI AND HIGH WAVES
}

\author{
Satoshi Kiso, Kansai University, sk15.arch@gmail.com \\ Tomohiro Yasuda, Kansai University, tomo@oceanwave.jp \\ Nobuhito Mori, DPRI, Kyoto University, mori@oceanwave.jp \\ Andrew Kennedy, University of Notre Dame, andrew.kennedy@nd.edu
}

\section{INTRODUCTION}

Boulders made of coral limestone transported shoreward have been observed many times in the tropics and subtropical coastal zones, and are called storm boulders or tsunami boulders. They can become lasting evidence of historical mega-tsunami or super typhoon occurrence during the past hundreds to thousands of years, even if no literature record remains. In recent years, a large number of surveys have been conducted worldwide, and the existence of large boulders has been found in several areas such as the Pacific Ocean, the Caribbean Sea, the Atlantic Ocean, and other regions. Since there is limited observational record of their detailed motion, movement limit, and spatial distribution of transport by gigantic tsunami or storm waves, detailed movement mechanisms are still poorly known. This increases the difficulty of developing a model of boulder transport, and interpreting field observations. These hydrodynamic conditions are also directly related to structural loads of interest to engineers and planners. This study aims to measure transport characteristics of coastal boulders through a series of experiments in a tsunami-wave laboratory flume.

\section{EXPERIMENTAL SETUP}

This study uses the Hybrid Tsunami Open Flume in Ujigawa lab, Kyoto University (HyTOFU), which can generate arbitrary tsunami waveforms or irregular storm waves. We selected six sizes $(D=4,5,6,7,10$, and 17 $\mathrm{cm}$ ) of limestone boulder models with specific gravity around 2.3, categorized into three general shapes for 18 total boulders. Model scale is set as $1 / 50$. HyTOFU features a flat reef $0.8 \mathrm{~m}$ above the flume bottom, with a 1:10 gradient slope connecting the two areas. Experimental conditions are changed as follows: three constant water depths $\left(h_{0}=0.74,0.79\right.$, and $\left.0.84 \mathrm{~m}\right)$; six tsunamis $(\mathrm{H}=0.025,0.05,0.075,0.1,0.125$, and $0.15 \mathrm{~m})$; three irregular waves $(\mathrm{Hs}=0.30 \mathrm{~m}, \mathrm{Tp}=2.55 \mathrm{~s} ; \mathrm{Hs}=0.22 \mathrm{~m}, \mathrm{Tp}=$ $2.12 \mathrm{~s}$; and $\mathrm{Hs}=0.16 \mathrm{~m}, \mathrm{Tp}=1.69 \mathrm{~s})$. Wave heights in the offshore and the onshore (every $1 \mathrm{~m}$ ) are measured by ten wave gauges. Final positions of boulders and movement type (sliding or rotation) were measured after each trial. Overhead $4 \mathrm{~K}$ video was taken, and movement characteristics are being analyzed using PIV. Static and dynamic friction coefficients are also measured, as are detailed boulder shapes.

\section{MAJOR RESULTS}

Boulders were much more movable by tsunamis than by storm waves. Transport characteristics are summarized by water level, wave height, diameter and final position of boulder under both conditions. Figure 1 and 2 show distributions of transport distance of boulders for the case of tsunami and storm waves, respectively. Black dots indicate measured value, and color map shows linearly interpolated values. In case of solitary wave, transport distance increases when the reef is dry. Transport distance is strongly affected by wave breaking point of solitary wave. On the other hand, in case of storm waves, transport distance increases when the reef is wet. Irregular waves continuously force to the boulders, and apparent weight become light in the submerged condition resulting smaller friction and movable condition.

\section{CONCLUSIONS}

The dynamics of boulder transport show a strong dependence on both detailed hydrodynamics and boulder properties, some of which have never been observed in the field. Largest transport distances are found for still water levels just below a flat shelf, and one long tsunami waves will transport boulders for much greater distances than many irregular storm waves.

\section{REFERENCES}

Kennedy, A., et al. (2016): Observations and modeling of coastal boulder transport and loading during super typhoon Haiyan, C.E.J., Vol.58, No.1, pp.1640004-1-25. Kennedy, A., et al. (2017): Extreme block and boulder transport along a cliffed coastline during super typhoon Haiyan, Mar. Geol., Vol. 383, No. 1 pp.65-77.

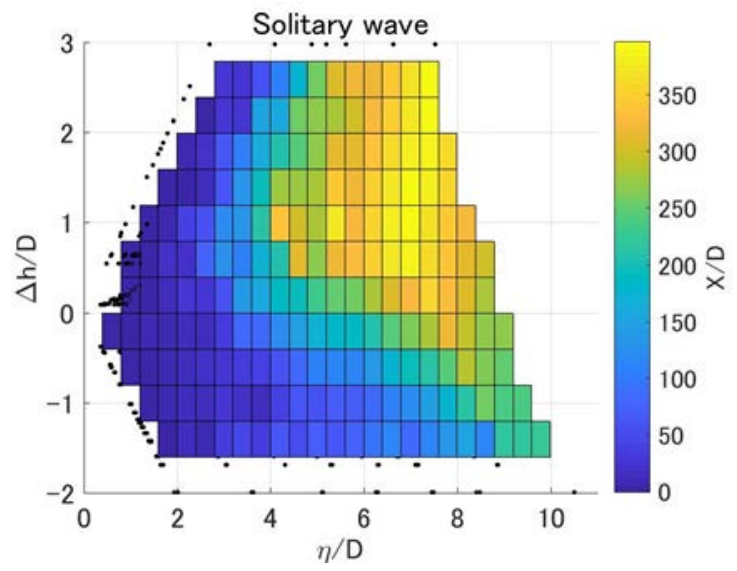

Figure 1 Transport characteristics by tsunami.

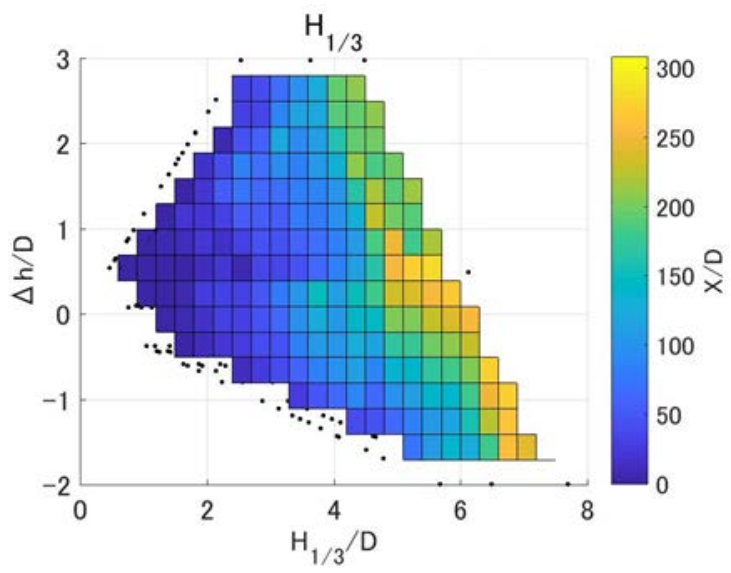

Figure 2. Transport characteristics by high waves. 